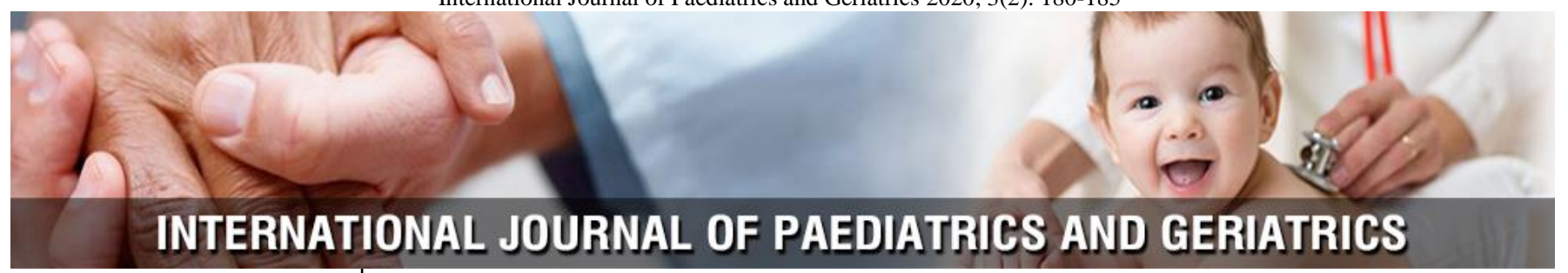

P-ISSN: 2664-3685

E-ISSN: $2664-3693$

IJPG 2020; 3(2): 180-185

Received: 09-10-2019

Accepted: 25-12-2019

Dr. VS Anjankumar MD

Associate Professor of

Pediatrics, Sri Venkateswara

Medical College, Tirupati,

Andhra Pradesh, India

Dr. K Sivaramudu

Assistant Professor,

Department of Pediatrics, Sri

Venkateswara Medical College

Tirupati, Andhra Pradesh,

India

Dr. I Bhaskar Naik

Assistant Professor,

Department of Pediatrics, Sri

Venkateswara Medical College

Tirupati, Andhra Pradesh,

India

Dr. T Jayachandra Naidu MD Professor, Department of

Pediatrics, Sri Venkateswara Medical College Tirupati,

Andhra Pradesh, India

Dr. R Chandhan Reddy Resident, Department of Pediatrics, Sri Venkateswara Medical College Tirupati, Andhra Pradesh, India

R Neha

Pharm. D Intern, Department of Pharmacy practice, Sri Padmavathi School of Pharmacy, Tiruchanoor, Tirupati, Andhra Pradesh, India
Corresponding Author: Dr. VS Anjankumar MD Associate Professor of Pediatrics, Sri Venkateswara Medical College, Tirupati, Andhra Pradesh, India

\section{Clinical profile and outcome of under nutrition among under five years children at nutritional rehabilitation centre in a tertiary care hospital}

\author{
VS Anjankumar MD, K Sivaramudu, I Bhaskar Naik, T Jayachandra \\ Naidu MD, R Chandhan Reddy and R Neha
}

DOI: https://doi.org/10.33545/26643685.2020.v3.i1c.91

\begin{abstract}
Introduction: Malnutrition is the gravest single threat to the world public health. Under nutrition is one of the most concerning health and development issues in India. The main aim was to describe the clinical profile of children aged less than 5 years diagnosed as Severe Acute Malnutrition and outcome of treatment at Nutrition Rehabilitation center.

Methods: A descriptive study conducted among 378 subjects for 1 year. Data collection was done on detailed history and examination of the subjects including anthropometry and analysed.

Results: The majority of children $(51.32 \%)$ were of $<12$ months. Males contribute major proportion in $(56.08 \%)$. Rural children are about $61.90 \%$, where most of the children belong to lower economical status $(51.86 \%)$.Most children recovered $87.30 \%$ and were no deaths during study.

Conclusion: There is a need to improve access to health care and need for chain of nutritional care at different levels of the community.
\end{abstract}

Keywords: malnutrition, under nutrition, severe acute malnutrition (SAM), nutrition rehabilitation center, nutitional care

\section{Introduction}

Malnutrition is the gravest single threat to the world public health. WHO estimates that malnutrition is the biggest contributor to child mortality in under five children, accounting for $54 \%$ child deaths worldwide, translating to unnecessary loss of about 3 million young lives every year ${ }^{[1]}$. Malnutrition refers to both undernutrition and overnutrition. Undernutrition is defined as the outcome of insufficient food intake (hunger) and repeated infectious diseases, it includes being underweight for one's age, too short for one's age (stunted), dangerously thin (wasted), and deficient in vitamins and minerals (micronutrient maInutrition) ${ }^{[2]}$. Overnutrition is defined as abnormal or excessive fat accumulation that may impair health; it results in overweight and obesity ${ }^{[3]}$.

Undernutrition is one of the most concerning health and development issues in India as in other parts of the world. Undernutrition encompasses stunting (chronic malnutrition), wasting (acute malnutrition) and deficiencies of micronutrients (essential vitamins and minerals). The high mortality and disease burden resulting from undernutrition call for urgent implementation of interventions to reduce their occurrence and consequences and this would include determined action on the social determinants of undernutrition ${ }^{[4]}$.

Nearly half of all deaths in children under 5 can be attributed to undernutrition. Undernutrition puts children at greater risk of dying from common infections, increases the frequency and severity of such infections, and contributes to delayed recovery. In addition, the interaction between undernutrition and infection can create a potentially lethal cycle of worsening illness and deteriorating nutritionalstatus ${ }^{[5]}$.

Malnutrition is more than a lack of food it is a combination of factors: insufficient protein, energy and micronutrients, frequent infections or disease, poor care and feeding practices, inadequate health services, and poor water and sanitation ${ }^{[6]}$.

In India, according to the National Survey (NFHS-3, 2005-06), 43 percent children under age of five years are underweight (low weight for age), 48 percent children under five are stunted (low height for age), 20 percent children under five years of age are wasted (low weight for height). Over 6 per cent of these children are severely wasted (<-3SD). 
Since 'wasting'denotes acute malnutrition, these children are said to have Severe Acute Malnutrition or SAM ${ }^{[4]}$. Severe acute malnutrition is a form of undernutrition defined by very low weight-for-height/length ( $Z$ - score below -3SD of the median WHO child growth standards), a mid-upper arm circumference $<115 \mathrm{~mm}$, or by the presence of nutritional edema. Children with SAM, when managed in specialized units with skilled manpower and adequate resources for nutrition rehabilitation have very high levels of survival ${ }^{[4]}$.

Nutrition Rehabilitation Center (NRC) is a unit in a health facility where children with severe acute malnutrition (SAM) who meet the defined admission criteria are admitted and provided with medical and nutritional therapeutic care ${ }^{[4]}$. The introduction of NRCs has brought uniformity in the management of children with severe acute malnutrition.

In India, usually a SAM child presents to health care facility with one of the infections or clinical profile of various underlying disorders rather than isolated growth failure. Early identification and proper management of complications (like pneumonia, diarrhea, and sepsis) plays a vital role in deciding outcome during nutritional rehabilitation in these children. Recovery may vary in these children. Recovery rate may also vary in different NRCs $[9$, 11].

Hence, the present study was undertaken to evaluate clinical profile and outcome of the children at nutrition rehabilitation center of our institute by assessing the relative contribution of various variables of malnourished children admitted to the NRC of our hospital.

\section{Aims and objectives}

1. To describe the clinical profile of children aged less than 5 years diagnosed as Severe Acute Malnutrition (SAM) and admitted at Nutrition Rehabilitation Centre, Tertiary Care Hospital.

2. To study the outcome of treatment at Nutrition Rehabilitation center and improvement in anthropometric status of discharged cases during a follow up period of 5 weeks from the date of discharge.

\section{Materials and methods}

This is a Hospital based Descriptive study done at Nutrition Rehabilitation Centre in Sri Venkateswara Ramnarain Ruia Government General Hospital, Department of pediatrics, Tirupati from 25 October 2016 to 24 October 2017.

All children under five years who were admitted at Nutrition Rehabilitation Centre in Sri Venkateswara Ramnarain Ruia Government General Hospital, Tirupati during the study period were included based on inclusion and exclusion criteria. Permission was obtained from institutional ethics committee, Sri Venkateswara Medical College, Tirupati. Study has been conducted after taking written informed consent from the mother or caretaker

\subsection{Inclusion criteria}

Children diagnosed with undernutrition aged less than 5 years at Nutrition Rehabilitation Centre, Tertiary Care Hospital during the study period.

\subsection{Exclusion criteria}

- Causes of severe acute malnutrition with feeding problems like cleft lip, cleft palate, cerebral palsy, global developmental delay were excluded.

- Critically ill children like children with congenital heart disease presenting with congestive cardiac failure, respiratory failure requiring mechanical ventilation were excluded from the study

\subsection{Admission criteria}

For children 6-59 months

\section{Any of the following}

1. Mid Upper Arm Circumference (MUAC) $<115 \mathrm{~mm}$ with or without any grade of oedema

2. Weight-for-height $<-3 \mathrm{SD}$ with or without any grade of oedema.

3. Bilateral pitting oedema $+/++$ (children with oedema +++ always need inpatient care)

Along with Anorexia (Loss of appetite), Fever (39 degree c) or Hypothermia $(<35 \mathrm{c})$, Persistent vomiting, Severe dehydration based on history and clinical examination, Not alert, very weak, apathetic, unconscious, convulsions, Hypoglycemia, Severe Anemia (severe palmar pallor), Severe pneumonia

Detailed history and examination of the child (including anthropometric measurements) was done. The clinical signs of micronutrient deficiency were assessed and relevant investigations done. Outcome was assessed in terms of improvement and discharge, defaulter (left against medical advice) and death. The data was entered in a data collection form A thorough general and systemic examination was done, and vital signs were observed and recorded.

A. Weight measurements -Infants under two years of age were weighed using a $25 \mathrm{~kg}$ Salter hanging scale while those above two years of age were weighed while standing on the measuring board. Weight for height is compared with references shown in Annexures 1\&2.

B. Length / Height measurements -In patients up to the age of 24 months, length was measured using a length board in the recumbent position by two examiners. For those above 24 months and who were able to walk, height was measured while standing using a height meter. Weight for height/length and $\mathrm{Z}$ score of less than -1 was indicated as mild -2 was indicated as moderate and -3 was indicated as severe wasting.

C. Mid-upper arm circumference (MUAC)Measurements were done midpoint between acromion and olecranon process by tape measure on the left arm. The reading was recorded to the nearest $0.1 \mathrm{~cm}$. Children with MUAC of $12.5-13$. Scm were mild, 11.0 to $12.5 \mathrm{~cm}$ were moderate and less than $11.5 \mathrm{~cm}$ were considered severe malnourished.

\section{Follow-up}

All the children discharged from the facility were followed up for 5 weeks with first follow up 7 days after discharge, second follow up 15 days after the first follow up and third follow up 15 days after second follow up. And anthropometric measurements were taken and measured against discharge measurements.

3.4 Data analysis: Data was entered in Microsoft Excel 2010 and analysed

3.5 Ethical considerations

Permission was obtained from institutional ethics 
committee, Sri Venkateswara Medical College, Tirupati before starting the study.

Child's mother or caretaker was explained about the condition and the study in their own language and consent was taken before the child is recruited into the study

\section{Results}

From 25 October 2016 to 24 October 2017, a total of 426 children aged less than 5 years were admitted in Nutritional Rehabilitation Centre in Department of Pediatrics at S.V.R.R.R.G.G. Hospital out of which 48 were excluded as per exclusion criteria and remaining 378 subjects were included and studied for clinical profile and outcome.

Mean age of distribution of SAM in the present study was $18.8+15$ in months. Most of the subjects were infants (up to 12 months) $(51.32 \%)$. Where males constitute $56.08 \%$ and females contributing to $43.92 \%$ and most of the children came from rural areas contributing to $61.90 \%$ showing poor nutritional status of rural population.

It was observed that children who did not receive exclusive breast feeding had more the chance of getting malnourished. Majority of the malnourished children (> 6 mths of age) were not exclusively breast fed for 6 months $(65.31 \%)$. In our study greater proportion of children were found to be unimmunized or partially immunized both contributing to $51.33 \%$ of the children.

Most of the children (124) stayed for less than 7 days contributing to $37.58 \%, 117$ children stayed for 7-14 days $(35.45 \%)$ and 89 children stayed for more than 14 days contributing to $26.97 \%$. The mean duration of stay was 10.62 days.

In the present study we observed that in the enrolled patients, most of the families of the patients belonged to Lower class (Class IV and V) of socioeconomic status according to Modified Kuppuswamy scale contributing to $51.86 \%$ (Class IV and V) showing that Severe acute malnutrition is seen in mostly in children belonging to lower socio economic status most common complication associated was gastrointestinal infections $(30.16 \%)$ followed by respiratory tract infection $(24.34 \%)$, Urinary tract infections (6.08\%), Malaria (4.23\%), Septicemia (3.96\%), Tuberculosis $(2.11 \%)$, HIV (1.05\%).

In the present study, out of 378 children admitted at NRC, most of the children (330) were recovered \& discharged from the facility contributing to $87.30 \%$ and there were no deaths during the period of study.

\begin{tabular}{|c|c|c|c|}
\hline Parameter & Description & Subjects & Percentage \\
\hline \multirow{3}{*}{ Age } & Up to 12 months & 194 & $51.32 \%$ \\
\hline & 13 months - 36 months & 130 & $34.31 \%$ \\
\hline & 36 months -60 months & 54 & $14.37 \%$ \\
\hline \multirow{2}{*}{ Gender } & Male & 212 & $56.08 \%$ \\
\hline & Female & 166 & $43.92 \%$ \\
\hline \multirow{2}{*}{ Region } & Rural & 234 & $61.90 \%$ \\
\hline & Urban & 144 & $38.10 \%$ \\
\hline \multirow{2}{*}{$\begin{array}{c}\text { Exclusive breastfeeding Upto } 6 \\
\text { Months }(\mathrm{n}=294)\end{array}$} & Not exclusively breast fed till 6 months of age & 192 & $65.31 \%$ \\
\hline & Exclusively breast fed till 6 months of age (topfed or mixed feeds) & 102 & $34.69 \%$ \\
\hline \multirow{3}{*}{ Immunisation Status } & Unimmunized & 46 & $12.16 \%$ \\
\hline & Partially immunized & 148 & $39.15 \%$ \\
\hline & Completely immunized & 184 & $48.67 \%$ \\
\hline \multirow{3}{*}{ Duration of Stay $(n=330)$} & $<7$ days & 124 & $37.58 \%$ \\
\hline & $7-14$ days & 117 & $35.45 \%$ \\
\hline & $>14$ days & 89 & $26.97 \%$ \\
\hline \multirow{5}{*}{ Socio-Economic Status } & Class I & 0 & 0 \\
\hline & Class II & 57 & $15.08 \%$ \\
\hline & Class III & 125 & $33.06 \%$ \\
\hline & Class IV & 166 & $43.92 \%$ \\
\hline & Class V & 30 & $07.94 \%$ \\
\hline \multirow{2}{*}{ Outcome of the Study } & Recovery & 340 & $87.30 \%$ \\
\hline & Default & 48 & $12.70 \%$ \\
\hline
\end{tabular}

\section{Complications based}

In the present study, most common complication associated was gastrointestinal infections $(30.16 \%)$ followed by respiratory tract infection $(24.34 \%)$, Urinary tract infections (6.08\%), Malaria (4.23\%), Septicemia (3.96\%), Tuberculosis $(2.11 \%)$, HIV (1.05\%).

In the present study, out of 330 children who were recovered \& discharged from NRC, 258 children came for first follow up visit with a dropout rate of 21.82 Of them, 206 children (79.85\%) had some weight gain when compared to the weight at discharge. 37 of them had weight loss and 15 of them had no change in weight when compared with weight at discharge.
248 children came for second follow up visit with a dropout rate of $24.85 \%$. Of them, 235 children had weight gain when compared with first follow up visit contributing to $94.76 \%$. 10 of the children had weight loss and 03 of them having no change in weight when compared to weight at first follow up visit.

The dropout rate for third follow up visit was 27.870 (238 children came for third follow up visit). The children who had weight gain when compared with second follow up visit was $231(97.05 \%)$ with 06 of them having weight loss and 01 of them having no change in weight when compared to weight at second follow up visit. 


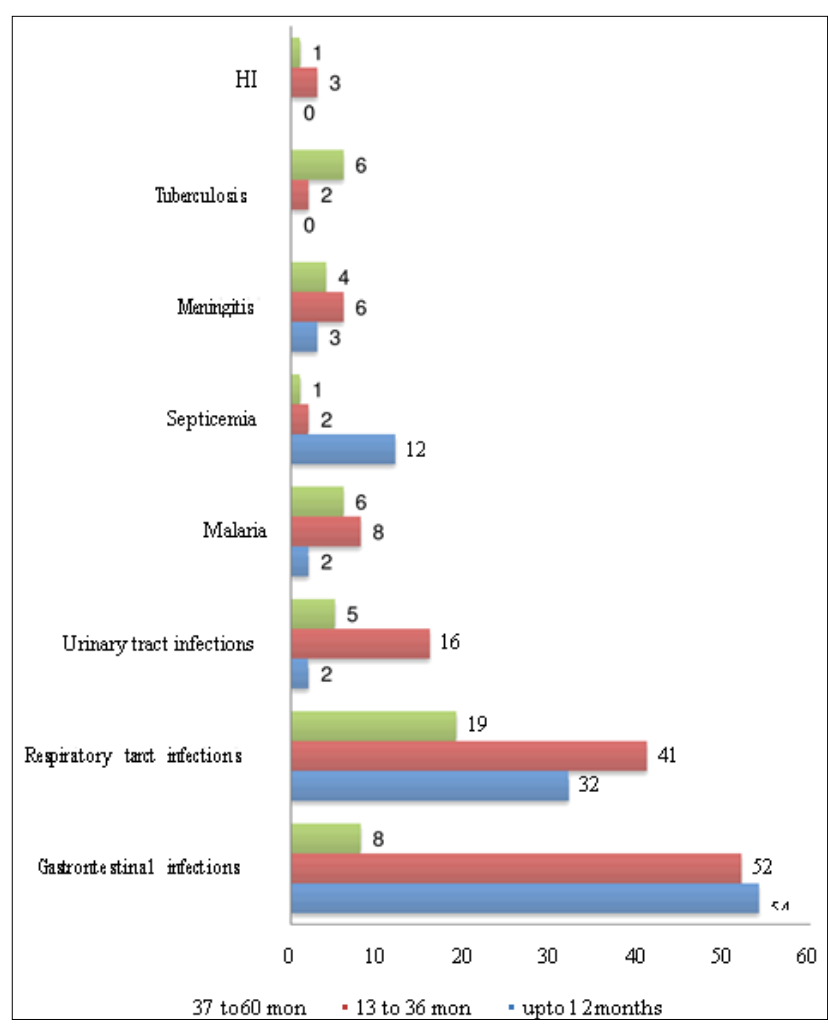

Fig 1: Age Wise Distribution of Complications in the Subjects under study

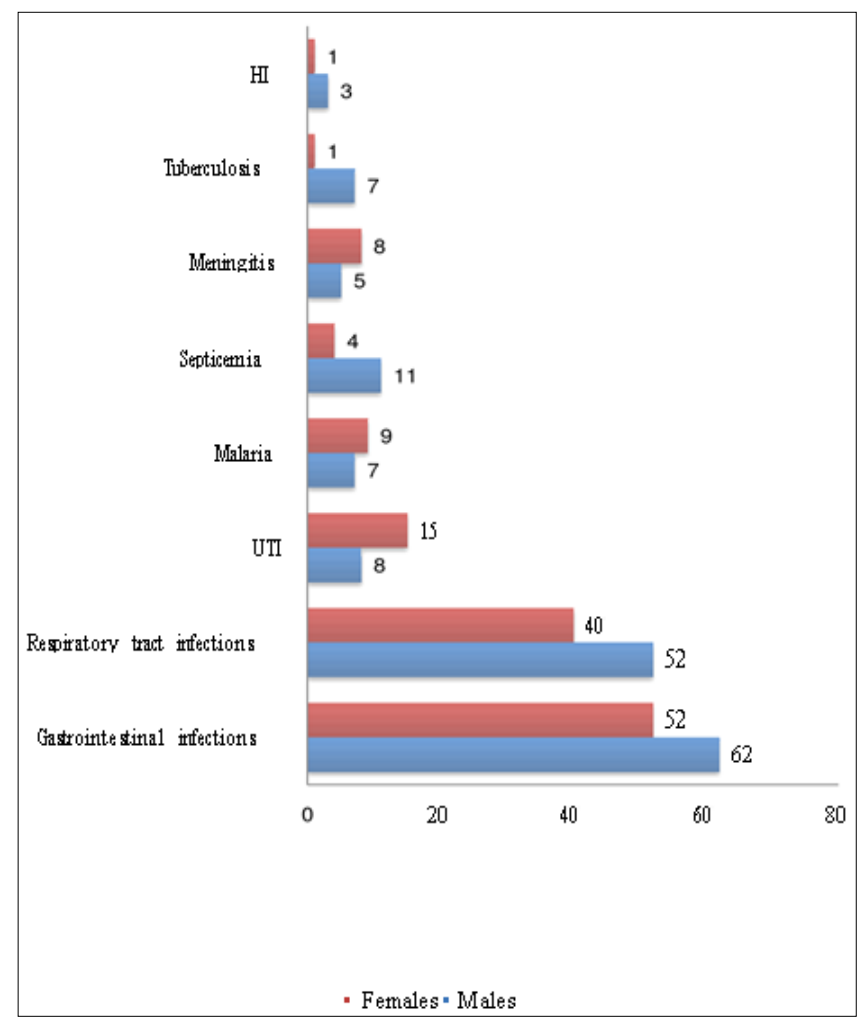

Fig 2: Gender wise distribution of complications in subjects under study

Table 2: Proportion of weight gain and weight loss at each follow up visit

\begin{tabular}{|c|c|c|c|c|}
\hline Follow up visits & $\begin{array}{c}\text { Dl'opout } \\
\text { Rate }\end{array}$ & $\begin{array}{c}\text { Weight } \\
\text { Gained }\end{array}$ & $\begin{array}{c}\text { Weight } \\
\text { Lost }\end{array}$ & $\begin{array}{c}\text { No Change in } \\
\text { Weight }\end{array}$ \\
\hline First follow up & $21.82 \%$ & 206 & 37 & 15 \\
\hline Second follow up & $24.85 \%$ & 235 & 10 & 03 \\
\hline Third follow up & $27.87 \%$ & 231 & 06 & 01 \\
\hline
\end{tabular}

\section{Discussion}

Malnutrition is the gravest single threat to the world public health. WHO estimates that malnutrition is the biggest contributor to child mortality in under five children, accounting for $54 \%$ child deaths worldwide, translating to unnecessary loss of about 3 million young lives every year. Malnutrition is the one of the leading causes of morbidity and mortality in children throughout the world. Severe Acute Malnutrition affects nearly twenty million under five children and contributes to one million child deaths yearly.

The mortality rate of children with complicated SAM that receive treatment in inpatient set ups has remained unacceptably high. (Heikens) Such high mortality in inpatient units has been attributed to complications such as infections and micronutrient deficiencies.

In initial 2-3 years of life rapid growth occurs and requirement of substrates for energy and building of tissue also increases, thus deficiency of protein, energy and other micronutrients in these years result in slowing of growth (malnutrition).

The mean age in months is relatively more in the present study i.e., 18.8 months compared to other studies i.e Sharma et al. ${ }^{[12]}$ in their study reported that prevalence of malnutrition is high in children less than 24 months. Similarly Mamidi et al. ${ }^{[13]}$ in their study reported that $71.1 \%$ of children were below 24 months. In our study males were more than females which is consistent studies done by Choudary et al. ${ }^{[14]}$, Ashraf et al. ${ }^{[15]}$ and Aneja et al. [16], in contrast Incidence of malnutrition was higher in females than males in studies conducted by Joshi et al. ${ }^{[17]}$, Rao et al. ${ }^{[18]}$, Singh et al. ${ }^{[19]}$, and Kumar et al. ${ }^{[20]}$.

The children admitted to NRC were more of rural children compared to urban children. Rural children contributed about $61.90 \%$ of the total children. This is similar to the results of the study undertaken by Choudary et al. ${ }^{[14]}$, Ashraf et al. ${ }^{[15]}$. Poor nutritional status of rural children compared to their urban counterparts is due to the cumulative effect of a series of less favorable conditions, including lower socioeconomic conditions, improper maternal prenatal and birthing care, poor quality of complementary feeding and poor immunization status.

In the enrolled patients most of the patients i.e., $51.86 \%$ of total children belong to lower socioeconomic status (Modified Kuppuswamy scale IV and V). Severe acute malnutrition was infrequent in upper socioeconomic class. Soni et al. ${ }^{[21]}$, Ashraf et al. ${ }^{[15]}$, in their studies reported that majority of malnourished children belonged to lower socioeconomic status (IV and V) i.e., $72.8 \%$ and $90 \%$ respectively. Likewise Rao et al. ${ }^{[18]}$, Singh et al. ${ }^{[19]}$, and Swaminathan et al. ${ }^{[22]}$, also reported that malnutrition is related to per capita income and socioeconomic inequality. This is mainly thought to be due to unavailability of food, poor purchasing power, inappropriate distribution and inadequate utilization might make the children vulnerable to malnutrition in a deprived community.

Breast milk is the best available food for infant and those who have been deprived of this, are expected to show a greater prevalence of malnutrition. In this study, majority of the children belonged to the group who were not exclusively breast fed up to 6 months of age $(65.31 \mathrm{O})$, showing the importance of exclusive breast feeding for at least first 6 months of life. Similarly, Mallik et al. ${ }^{[23]}$ also reported that among the children less than two years, malnutrition was observed significantly more in those who were not 
exclusively breast fed than the children exclusively breast fed for 4- 6 months.

This could be explained as breast milk is a complete source of all vitamins, proteins, fat and carbohydrate for the growing child and also decreases chances of infections in exclusively breast feed infants in the initial six month of age.

It was observed that $12.16 \%$ were unimmunized and 39.15 $\%$ were partially immunized in the study which was supported by Choudary et al. ${ }^{[14]}$ and Kumar et al. ${ }^{[20]}$

Sharma et al. ${ }^{[12]}$, Shah et al. ${ }^{[24]}$ and Devdas et al. ${ }^{[25]}$ observed that better the socioeconomic and educational status of mothers; better was the immunization status of children. It is due to the fact that most of the children in our study belonged to rural area and socioeconomic status was also low. A substantial proportion of rural parents are unaware of the protective value of immunization.

In our study the most common complication associated with severe acute malnutrition was gastrointestinal infections $(30.16 \%)$ followed by respiratory tract infection $(24.34 \%)$, Urinary tract infections (7.83\%), Septicemia (3.96\%), Malaria (3.17\%), which was consistent with study conducted by Choudary et al. ${ }^{[14]}$, Sharma et al. ${ }^{[12]}$, Bernal et al. ${ }^{[26]}$.

In the present study, most of the children (124) stayed for less than 7 days contributing to $37.58 \%$, the mean duration of stay was 10.62 days. The duration of stay was low in our study because most of the patients were opting for early discharge once the complications were under control.

of the 330 children discharged from NRC, 278 (84.24\%) showed some weight gain during the hospital stay and minimal weight gain of $5 \mathrm{gm} / \mathrm{kg} /$ day for 3 consecutive days was observed in 201 children $(60.90 \%)$. Target weight of 15 $\%$ weight gain was observed in $51(15.45 \%)$ children. The mean weight gain was $6.33 \mathrm{gm} / \mathrm{kg} / \mathrm{day}$, which is less than the mean weight gain observed by Singh $\mathrm{K}$ et al. ${ }^{[27]}$ but more than that observed by Teferi E et al. ${ }^{[28]}$ and Dhanalakshmi et al. ${ }^{[29]}$. The mean weight gain and duration of stay was low in our study because most of the mothers or caretakers were opting for early discharge once the complications were under control.

In our study, most of the children were considered cured (either free from complications or achieved target weight gain) contributing to $87.30 \%$ (recovery rate), with a defaulter rate of $12.70 \%$ and there were no deaths during the period of study. The recovery rate was consistent with studies conducted by Berti A et al. ${ }^{[30]}$, Aguayo VM et al. Our NRC achieved good outcome with respect to recovery rate of $87.30 \%$, Death rate of $<10 \%$, defaulter rate of $<15 \%$ which is acceptable according to the WHO protocol.

In the present study, out of 330 children who were recovered \& discharged from NRC, 258 children came for first follow up visit with a drop outrateof $21.82 \%$. The dropout rate for second follow up visit was $24.85 \%$. The dropout rate for third follow up visit was $27.87 \%$. The dropout rate in our study was higher than that observed by Taneja et al. ${ }^{[32]}$ but less than that observed by Bhimani NR et al. ${ }^{[33]}$. This is probably due to majority of the study subjects belong to rural areas and their socioeconomic status was low.

Our study also reveals increasing dropout rates with each successive follow up visit which is consistent with the studies done by Taneja et al. ${ }^{[32]}$ and Bhimani NR et al. ${ }^{[33]}$.

\section{Limitations of the study}

This is a hospital based descriptive study and its results cannot be extrapolated to the general population.

\section{Conclusion}

Undernourished children have significantly higher risk of morbidity and mortality. Severe acute malnutrition is one of leading cause of mortality and morbidity in our country. Early identification and proper management of complications (like pneumonia, diarrhea, and sepsis) play a vital role in deciding outcome during nutritional rehabilitation in these children.

There is need for a community based programme, which complements and links the facility based interventions at NRC. As the mother or caretakers were opting for early discharge and there were dropouts in the follow-up period, there is a need to improve access to health care in the community and there is a need for chain of nutritional care at different levels of the community by linking Health workers (like ASHA, ANM, AWW) to provide a continuum of nutritional care. In other words, effective management of SAM must be based on the basic principle of "Continuum of Care"-from the home and community, to the health center/health facility and back again.

\section{References}

1. Parthasarathy A. IAP textbook of pediatrics. 6th ed. New Delhi: Jaypee, the Health Sciences Publisher, 2016, 152-172.

2. UNICEF - Progress for Children - What is undernutrition? [Internet]. Unicef.org. 2017 [cited 5 October 2017]. Available from: https://www.unicef.org/progressforchildren/2006n4/ind ex undernutrition.ht

3. [Internet]. 2017 [cited 5 October 2017]. Available from: http://www.who.int/pmnch/topics/part

publications/KS18-high.pdf

4. Operational Guidelines on Facility-Based Management of Children with Severe Acute Malnutrition. New Delhi: National Rural Health Mission, Ministry of Health and Family Welfare [Internet]. 2017 [cited 5 October 2011-2017]. Available from: http://nhm.gov.in/images/pdf/ programmes/ childhealth/guidelines/operational guidelines on fbmc with sam.pdf

5. Malnutrition unicef data [Internet]. Unicef data. [Cited 5 October 2017]. Available from: https://data.unicef.org/topic/nutrition/ malnutrition/\#

6. The faces of malnutrition [Internet]. UNICEF. [Cited 5 October 2017]. Available from: https://www.unicef.org/nutrition/index faces-ofmalnutrition.htmI\#1

7. International Institute for Population Sciences (IIPS) and Macro International. National Family Health Survey (NFHS-3), 2007; 06(2), Mumbai: IIPS, India, 2005, 1-168.

8. Ministry of Health and Family Welfare Government of India, Operational guideline: facility based management of SAM children, Module, 2011, 4-6. Available from: http://www.rajswasthya.nic.in/MTC\%20GuideIine-\%20 MOHFW.pdf

9. Bharathi S, Anuradha K, Rao JV. An experience at a tertiary level hospital NRC in management of severe acute malnutrition in children aged between 6-59 
months adopting World Health Organization recommendations. Res Health Sci. 2016; 1(1):41-50.

10. Saaka M, Osman SM, Amponsem A, Ziem JB, AbdulMumin A, Akanbong $\mathrm{P}$ et al. Treatment outcome of severe acute malnutrition cases at the tamale teaching hospital. J Nutrition Metabol. 2015; 2015:1-8.

11. Singh K, Badgaiyan N, Ranjan A, Dixit HO, Kaushik A, Kushwaha KP et al. Management of children with severe acute malnutrition: experience of nutritional rehabilitation centres in Uttar Pradesh, India. Indian Pediatr. 2014; 51:21-5.

12. Sharma LM. P1190 A study of malnutrition and associated infection in children in urban private hospital in India, Journal of Pediatric Gastroenterology and Nutrition. 2004; 39(1):S509.

13. Mamidi RS, Kulkarni B, Radhakrishna KV, Shtrugna V. Hospital based nutrition rehabilitation of sefverely undernourished children using energy dense local foods. Indian Pediatr. 2010; 47(8):687-691.

14. Choudary M, Sharma D, Nagar RP, Gupta BD, Nagar T et al. Clinical profile of severe acute malnutrition in Western Rajasthan: A prospective Observational Study from India. J Pediatr Neonatal Care. 2015; 2(1):00057. DOI: 10.15406/jnm. 2015.02.00057

15. Ashraf S, Javed MT, Abbas N, Aysha H, Hameed S. Malnutrition in diseased children with reference to age, sex, socioeconomic status and area of Iiving, Int J Agri Biol. 2001; 3(4):419-422.

16. Aneja B, Singh P, Tandon M, Pathak P, Singh C et al. Etological factors of malnutrition among infants in two urban slums of Delhi. Indian Pediatr. 2001; 38(2):160165.

17. Joshi S, Walgankar SS. Epidemiology of malnutrition in a rural field practice area of navi Mumbai, Indian $\mathbf{J}$ Prev Soc Med. 2004; 35(1 and 2):80-84.

18. Rao S, Joshi SB, Kelkar RS. Change in nutritional status and morbidity over time among preschool children from slums in Pune India. Indian Pediatr. 2000; 37(10):1060-1671.

19. Singh MB, Fotedar R, Laxminarayan J, Anand PK. Studies on nutritional status of children aged 0-5 years in a drought affected desert area of Western Rajasthan, India. Public Health Nutr. 2006; 9(8):961-967.

20. Kumar S, Grefenstette JJ, Galloway D, Albert SM, Burke DS Kumar et al. respond. Am J Public Health. 2014; 104(1):e1-2. Doi: 10.2105/AJPH.2013.301676.Epub 2013 Nov 14.

21. Soni AL, Singh RN, Gupta BD. Nutritional Disorders in rural Rajasthan. Indian Pediatr. 1980; 47(3):199-202.

22. Swaminathan MC, Jyothi KK, Singh R, Madhavan S, Gopalan C. A semilongitudinal study of growth of Indian Children and the related factors. Indian Pediatr. 1964; 1:255-263.

23. Mallik S, Mitra SP, Basu SS, Roy A, Saha A et al. Malnutrition: A missed opportunity to treat at tertiary care. Indian Journal of Community Medicine. 2006; 31(3):196-197.

24. Shah PM. Report of nutrition subcommittee of the Indian Academy of pediatrics. Indian Pediatrics. 1972; 9(6):360.

25. Devadas RP, Rajlakshmi R, Kaveri R. Influence of family income and parent's education on the nutritional status of preschool children. Indian Journal of Nutrition and Dietetics. 1980; 17(7):237-244.
26. Bernal C, Velasquez C, Alcaraz G, Botero J. Treatment of severe Malnutrition in children: Experience in implementing the WHO Guidelines in Turbo, CoIumbio. J Pediatr GastroentoI Nutr. 2008; 46(3):322328.

27. Singh K, Badgaiyan N, Ranjan A, Dixit HO, Kaushik A, Kushwaha $\mathrm{K}$ et al. Management of children with severe acute malnutrition: experience of nutritional rehabilitation centres in Uttar Pradesh, India. Indian Pediatr. 2014; 51:21.

28. Teferi E, Lera M, Sita S, Bogale Z, Datiko DG, Yassin MA. Treatment outcome of children with severe acute malnutrition admitted to therapeutic feeding centres in Southern Region of Ethiopia. Ethiopia J Health Develop. 2014; 24:234-8.

29. Dhanalakshmi K, Devi CG. Theoutcome of severe acute malnutrition children admitted to Nutrition Rehabilitation Centre of a tertiary level care hospital. Int J Contemp Pediatr. 2017; 4:801-3.

30. Berti A, Bregani ER, Manenti F, Pizzi C. Outcome of severely malnourished children treated according to UNICEF 2004 guieline: a one year experience in a zone hospital in rural Ethiopia. Trans R Soc Trop Med Hyg. 2008; 102:939-944.

31. Aguayo VM, Jacob S, Badgaiyan N, Chandra P, Kumar A, Singh K. Providing care for children with severe acute malnutrition in India: new evidence from Jharkhand. Public Health Nutrition, 2012, 1-6.

32. Taneja G, Dixit S, Khatri A, Raghunath D, Yesikar V, Chourasiya S. A study to evaluate the effect of nutritional intervention measures on admitted children in selected nutrition rehabilitation centers of Indore and Ujjain divisions of the state of Madhya Pradesh (India), 2017.

33. Bhimani NR, Vachhani PV, Kartha GP. A study to evaluate the effects of nutritional intervention measures on children admitted in the nutritional rehabilitation center (BalSanjeevani Kendra) of Surendranagar district. Int. J Res Med Sci. 2015; 3(8):1989-93. 